\title{
Clinical Practice Education: Perspectives from Internship and Externship Experiences
}

\author{
Carol Lynne Collins
}

$\mathbf{T}$ THE EXPERIENTIAL programs are an integral part of preparing pharmacy students for future practice. Although pharmacy started out as an apprenticeship trade, formal curriculums in the early twentieth century focused on the basic science education patterned after the European curriculums. Fifty years later, colleges and schools of pharmacy realized the importance of incorporating applied sciences taught by practitioners. ${ }^{1}$ The University of Washington was the first school of pharmacy to attempt this integration in 1944. Labeled the "Washington Experiment," this course used pharmacists and pharmacies to train students. ${ }^{2}$ It was subsequently dropped. Over the next 30 years other projects were attempted that form the basis for current experiential programs. At the same time, state boards of pharmacy adopted guidelines requiring work experience that is supervised by practicing pharmacists prior to licensure. Academia and the pharmaceutical profession now acknowledge practitioners as an integral part of the education process for pharmacy students.

This article addresses experiential training from the internship and externship perspective. In order to continue, these terms must be defined. The American Association of Colleges of Pharmacy (AACP) provide the following definitions.

Internship. The term "internship," as used in this text means the 1,500 hour practical experience requirement contained in most state pharmacy practice acts and maintained as a condition for interstate reciprocity of licenses. It may include postgraduation experience, supervised practice during summer vacations, limited amounts of experience gained concurrent with attendance at a college of pharmacy, and experience gained during college coordinated externship and clinical clerkship programs. $^{3}$

Externship. The term "externship," as used in this text is defined as a college coordinated practical experience program with the following characteristics: (1) It is conducted outside the classroom in licensed pharmacies. (2) It includes broad experiences in all distributive and patient oriented practice tasks. (3) It is supervised by a pharmacist preceptor with a one to one teaching and supervisory relationship between preceptor and extern. (4) It is a component of the college's curriculum for which academic credit is given. (5) It has been evaluated and approved by the state board of pharmacy.

Clerkship. The term "clerkship" or "clinical clerkship," as used in this text, is defined as a college coordinated practical experience program with the following characteristics: (1) It is conducted in patient care settings where the student is provided with actual experiences in patient care. (2) Emphasis is placed on all phases of drug therapy relative to the disease states of individual patients. (3) Primary student activities involve provision of clinical services on either an outpatient or an inpatient basis. (4) General drug distributive functions may be minimized. (5) It has been evaluated and approved by the state board of pharmacy. (6) It is a component of the college's curriculum for which academic credit is given.

These definitions allude to several issues facing state boards and pharmacy educators involved in internship and externship programs. The first issue is who bears the ultimate responsibility for experiential training. Specifically, how should state boards, schools of pharmacy, and the American Council on Pharmacy Education (ACPE) interact to provide quality experiential programs? The second issue is who provides the supervision and preceptorship of these programs and should there be a specified ratio for preceptors and students. The third issue is what competencies should be addressed. Last, but certainly not least, is how to insure the quality of experiential programs.

State boards bear the responsibility for internship and the schools of pharmacy bear the responsibility for externship and clerkship as previously described. However, it is also clear that an overlap exists. Prior to the development of experiential programs at the schools of pharmacy, the state boards took an active role in structuring internship programs. Legislation mandating numbers of hours, preceptor to intern

From the University of Michigan College of Pharmacy, Ann Arbor, $M I$.

Address reprint requests to Carol L. Collins, Pharm D. Clinical Assistant Professor/Externship Coordinator, University of Michigan College of Pharmacy, 1033 College of Pharmacy, Ann Arbor, MI 48109-1065.

(1990 by W.B. Saunders Company.

0897-1900/90/0302-0007\$5.00/0 
ratio, and documentation with the state board was initiated on an individual state basis. Hours required ranged from 400 to 2,000. Variation in requirements for preceptors also existed. The programs required an affidavit from the preceptor to document the hours.

As the schools of pharmacy developed experiential programs, a new trend occurred. Faculty were asked to participate with the state boards in structuring internship programs. In addition, schools of pharmacy began requesting that state boards approve their programs and accept them as fulfilling all or part of the internship requirement.

Today, state boards maintain the ultimate responsibility for internship but often delegate that responsibility to the schools of pharmacy. All states accept at least part of the hours from externship and clerkship programs to fulfill the

\section{Academia and the pharmaceutical profession now acknowledge practitioners as an integral part of the educational process for pharmacy students.}

internship requirements. In fact, Michigan State Board of Pharmacy has approved the University of Michigan College of Pharmacy's program (200 hours of externship, 1,400 hours of clerkship) since 1983 to fulfill the 1,000 hour internship requirement. In Florida, students must complete internship hours outside of externship and clerkship experiences. However, the internship sites are approved and monitored by a faculty member at the schools of pharmacy. The $\mathrm{Na}$ tional Association of Boards of Pharmacy have supported this trend by lifting the ceiling on the suggested 400 hours limit for internship hours granted from college-sponsored programs. ${ }^{4}$

The American Council on Pharmacy Education adopted standards fostering the expansion of college of pharmacy involvement in coordinating the practical experience programs.
The Council believes that the experiences students gain in the clinical courses (including clerkships and externships) should be of such caliber so as to serve in lieu of the internship requirement for licensure. The council expects, therefore, that a curriculum be designed to include an externship and other clinical components that will lead to the degree of professional competence in students required for admission to the licensure examination. The externship will provide the student with experiences in a variety of patient care settings where his work will be supervised by a number of practicing pharmacists, qualified to serve as preceptors. The externship will be guided by a policy established by the faculty, one member of which will be responsible for directing and coordinating the program. ${ }^{s}$

The ACPE currently serves as the accrediting body for college programs including externship.

In developing internship programs, state boards recognized the importance that preceptors have as role models for pharmacy interns. Criteria were developed and registration or licensure were required in most states. The most common criteria, in addition to current licensure as a pharmacist, was a year of practice. Thus, the state boards recognized the value of an on-the-job experience that could be relayed to an intern.

Schools of pharmacy also recognized the importance of including practitioners in the experiential programs. Although many clerkship rotations were developed by faculty, schools turned to practitioners to provide preceptorship for the externship programs. Today schools of pharmacy rely heavily on practitioner educators for both externship and clerkship programs.

The role of practitioner educators should not be underestimated. They form the first role models for pharmacy students and as such, influence the student's perception of pharmacy practice in the "real world." Practitioner educators also form a link for schools of pharmacy to actual practice settings and an opportunity to evaluate whether pharmacy curriculums are adequately preparing students for practice.

The issue has now shifted from whether practitioners should be preceptors for internship and externship programs to encouraging more practitioners to participate. Schools of pharmacy and state boards are focusing more attention to training and recognition programs for practitioner educators. The NABP along with the AACP published "The Internship Experience: A manual for pharmacy preceptors and interns" in 
$1980 .^{6}$ This document provides the basis for many current intern and externship programs. Guidelines for preceptors, sites, and competencies are outlined that are still valid today. Many states have developed similar manuals. California adopted a checklist of competencies to help guide preceptors. Schools of pharmacy have instituted workshops such as the AACP preceptor training program. In addition, experiential program coordinators at the schools are working to create adjunct and nontenure tract faculty appointments, honoraria programs, and other recognition programs to support the practitioner educators. Industry and professional associations also support efforts to recognize practitioner educators. Both Syntex and the American Apothecary Association sponsor preceptor of the year

\section{Practitioner educators form the first role models for pharmacy students and as such, influence the student's perception of pharmacy practice in the "real world."}

awards. These efforts should and will continue to support and recognize the volunteer efforts of practitioner educators.

The issue of ratio of preceptor to intern or externship student is currently under debate. For internship, most states require a one to one or one to two ratio. All states require that an intern be under direct supervision of a practicing pharmacist. Of note is that the AACP provides a ratio for externship of one to one but no such guideline for clerkship. ${ }^{3}$ This is most likely due to the recognition that many schools of pharmacy are still developing their resources (ie, preceptors and sites for clerkship experiences). Although no studies have been conducted that correlate the ratio to the educational outcome, most faculty accept that students must receive close supervision and one to one interaction to obtain the maximal benefit from experiential programs. The supervision is critical not only from an educational point of view but also because patient care is affected by the student's actions.

Pharmacy has gone through an evolution in its role in the health care system, in addition to the educational process, over the last fifty years. Therefore, the direction and competencies stressed in the experiential programs are continually evaluated and revised. Moving from a basic science orientation to clinical application has proved to be extremely difficult in this respect. Initial apprenticeship programs had very specific techniques to be taught and evaluated relative to compounding. As the basic science curriculum developed, specific course objectives and exams could be identified. The same approach was applied to experiential programs. However, the activities and abilities that form a competent practitioner in the actual practice setting are not so easily defined or reduced to objective measures.

From the definition of externship, both distributive and patient oriented skills should be addressed. The following areas are a part of this process. (1) Obtaining a comprehensive patient profile including prescription drug use, nonprescription drug use, disease states, allergies, and recreational drug use. (2) Reviewing prescriptions for safety and efficacy given the patient's profile. (3) Accurately filling and labeling the prescription given current product information and current laws. (4) Giving the patient adequate information, both verbal and written, to insure the proper use of the medication. (5) To provide information or resources regarding adjunct equipment or services that could improve the patient's medical care and quality of life. (6) To understand the basic management of the pharmacy. Looking at the objectives, externship appears to address the overall practice of pharmacy and is similar to APhA-AACP standards of practice. ${ }^{7}$ Clerkship stresses the patient care aspects. Many faculty feel that as clinical practice has evolved, most pharmacists are involved in a blend of patient care and distributive functions and that the distinction between externship and clerkship rotations is not clear. In addition, just as state boards recognize unique internship experiences, schools of pharmacies are allowing students to fulfill part of their experiential program in unique settings such as industry, associa- 
tion work, and administration. These generally fall under the clerkship label even thought they are not primary patient care rotations. State boards have generally recognized that pharmacy practice is not limited to traditional settings. With the development of more intensive patient oriented services and unique settings, such as industry, that require research and administrative skills, internship requirements have allowed for a specified number of hours (400 to 600 ) to come from such programs pursuant to a review by the state board or specially appointed committee.

Although from the previous discussions, providing practical experiences in actual practice situations under the supervision of practitioners is regarded as an integral part of the pharmacy student's education and the identification of objectives is clear, another issue still remains. How can quality and the goal of producing

\section{Pharmacy has gone through an evolution in its role in the health care system, in addition to the educational process, over the last fifty years.}

competent practitioners be ensured in the experiential programs?

A number of different methods have been applied to insure quality in both internship and externship programs. These include total number of hours required, timing of these hours, creating criteria for preceptors and sites, requiring experience in particular practice settings, using checklists and evaluation tools to structure the experience, affidavits and other mechanisms of documenting progress of internship with the state board, site visits by state board inspectors and externship coordinators, and review of externship programs by both the state board and ACPE.

The issue of total number of hours as a way to insure the quality of the internship program is still in debate. Similar to the preceptor/student ratio, no studies exist to guide state boards and schools of pharmacy. In 1974, NABP set a general standard of 1,500 hours as a condition of licensure by reciprocity. ${ }^{8}$ State boards still vary the requirement from a low of 400 hours to a high of 2,000 hours. Even though a correlation between a particular number of hours of internship insuring a competent practitioner has not been proven, it intuitively makes sense and is an extremely easy criteria to institute and monitor.

A second method of insuring quality by number of hours is to define when the hours may be obtained. All state boards and most schools agree that a portion of the didactic professional curriculum should be completed prior to any practical experience. Most commonly, state boards have required students to complete the first professional year of a pharmacy curriculum before allowing licensure as an intern. Although this criteria makes sense, it would be more meaningful if schools of pharmacy were standardized as to the curriculum of that first year. Some state boards have thought that hours should be obtained within a short period prior to licensure. A common requirement is that 500 of the 1,500 hours be obtained within six months prior to the licensure exam. Some state boards require hours postgraduation during the period between taking the licensure exam and actually becoming a licensed pharmacist. This would hopefully insure on-the-job training for a pharmacist's first position.

NABP and AACP set the following minimum criteria for preceptors. ${ }^{9}$ (1) The preceptor is licensed in the jurisdiction in which he/she practices pharmacy. Colleges and boards may establish additional educational and experience requirements in their respective programs. (2) The preceptor should participate actively in continuing education programs and preceptor training conferences. (3) The preceptor has practiced pharmacy for at least one year. (4) The preceptor has demonstrated competence as a teacher, effectively combining instruction and supervision, and using good communication skills in teaching and practice. (5) The preceptor, and all pharmacists at the training site, has maintained an outstanding ethical and legal compliance record. (6) The preceptor should participate actively in local, state, and national professional association activities. All state boards have adopted criteria one and three. Most boards, particularly in those states with mandatory continuing education, have 
adopted criteria two. Although some state boards have adopted criteria four, five, and six, these criteria are much more difficult to measure. Most schools of pharmacy have adopted these criteria and attempt to measure criteria four, five, and six through student evaluations, site visits, and individual meetings with the preceptors.

Criteria for traditional pharmacy practice sites have also been established. ${ }^{9}$ (1) The scope of pharmaceutical services provided and the volume and variety of prescription, over-the-counter drugs and medical-surgical devices dispensed should be suitable to furnish a wide range of general practice experiences. Large pharmacies with differentiated responsibilities and tasks among pharmacists should provide for a systematic rotation of intern experiences through all general practice activities. (2) The pharmacy should maintain a patient-oriented practice. The use of patient profiles is encouraged. Hospital pharmacies should provide opportunity for chart review. (3) The pharmacy is clean, orderly, well lighted, and presents an acceptable professional appearance. (4) The pharmacy routinely provides health care information to patients and other health care professionals. (5) The pharmacy maintains an acceptable professional library. (6) Pharmacies providing services on a limited, differentiated, or specialized basis should be considered as internship training sites, ie, nuclear pharmacies, skilled nursing home pharmacies. However, care should be taken to limit the amount of training time in such pharmacies so as to permit adequate experience in general practice pharmacies in which all of the generalized responsibilities and tasks of practice may be experienced. Most states have adopted criteria three and five, which are easily measured and documented. For criteria five, many states have actually specified certain mandatory texts above the usual requirements for a licensed pharmacy. Some states have required special registration of certification of a site for internship in addition to licensing preceptors. Others have set criteria, but only require the preceptor to be specifically licensed or registered. Some states have not addressed criteria for sites in relation to internship other than that the pharmacy is currently licensed with the state.

The above criteria also allude to the fact that hours should be obtained in certain practice settings. Concern has been raised by state boards and practitioners that as opportunities in unique settings with a more limited scope of practice and as the Pharm D degree becomes more prevalent, traditional practice should not be minimized. Community practitioners are particularly concerned because the impression of the Pharm D degree is that institutional and specialized practice is emphasized. Some state boards have addressed the issue by requiring that a specified number of hours must be obtained in a community pharmacy, hospital pharmacy, or both. Other states, such as California, have attempted competency checklists to insure that a wide variety of experiences are obtained during internship. Most states have not been successful in mandating experience in both hospital and community practice but have been successful in limiting the number of hours of truly "nontraditional" practice. ACPE in its accreditation process reviews college-based programs and looks for a balance between externship and clerkship activities and curriculums that address both hospital and community practice. As the health care system evolves differentiating between hospital, community, and "nontraditional" practice may become even more difficult.

Tools for structuring and evaluating experiential programs have been discussed since the early 1970s. Today, experiential coordinators and state boards are wrestling with the concept of a competency measure. A number of activities and objectives have been identified for internship and externship, but much debate is still given as to which ones and to what level these must be addressed to produce a "competent" practitioner. Table 1 is one attempt to address this issue. Many schools of pharmacy and state boards have developed checklists of competencies to structure activities. This list allows for the fact that some competencies may be best accomplished by reading assignments and discussions, whereas others require demonstration projects or actual performance of the task.

More difficult yet is the issue of evaluating experiential programs from a competency perspective. In addition to the preceptor providing feedback and evaluation to the student, a quality internship or externship program should include an evaluation of the preceptor and site by the student. Figure 1 shows the interaction between objectives and evaluation. Many forms use a 
Table 1. Selected Portions of the Joint Committee on Internship Checklist

\begin{tabular}{|c|}
\hline Select \\
\hline $\begin{array}{l}\text { Establishes drug quality specifications for drugs to be pur- } \\
\text { chased }\end{array}$ \\
\hline Compounding prescriptions \\
\hline $\begin{array}{l}\text { Interprets and evaluates prescription order for physical and } \\
\text { chemical compatibility }\end{array}$ \\
\hline Dispensing prescriptions \\
\hline Receives order and determines priority of handling \\
\hline Monitoring and evaluating therapy \\
\hline $\begin{array}{l}\text { Interviews the patient or his/her agent to obtain informa- } \\
\text { tion for entry into patient record, patient profile, or family } \\
\text { health record }\end{array}$ \\
\hline Communicating with patients about legend drugs \\
\hline $\begin{array}{l}\text { Makes recommendations to the patient regarding drug } \\
\text { therapy }\end{array}$ \\
\hline $\begin{array}{l}\text { Communicating with patients on selection of over-the-counter } \\
\text { drugs and medical/surgical supplies }\end{array}$ \\
\hline $\begin{array}{l}\text { Consults with patient to properly identify symptoms in or- } \\
\text { der to advise patient for self-medication }\end{array}$ \\
\hline Communicating with health care professionals \\
\hline $\begin{array}{l}\text { Makes recommendations regarding drug therapy to the } \\
\text { physician, or other persons involved with the patient's } \\
\text { care }\end{array}$ \\
\hline Maintaining drug information \\
\hline $\begin{array}{l}\text { Selects, evaluates, organizes, maintains, and uses a current } \\
\text { library of drug information }\end{array}$ \\
\hline Maintaining professional and ethical standards \\
\hline $\begin{array}{l}\text { Complies with legal and professional standards relating to } \\
\text { practice and to operation of the pharmacy }\end{array}$ \\
\hline Providing emergency pharmacy services \\
\hline $\begin{array}{l}\text { Provides information and/or referral in emergency cases } \\
\text { involving ingestion of toxic substances }\end{array}$ \\
\hline General public health and civic responsibilities \\
\hline Serves as a member of governmental health boards \\
\hline Managing pharmacy operations \\
\hline $\begin{array}{l}\text { Establishes and/or implements written policies and proce- } \\
\text { dures for pharmacy operations }\end{array}$ \\
\hline
\end{tabular}

rating scale to provide some objectivity and to ultimately assign a grade to the student for their performance during the rotation. Currently, behavioral anchors that correlate such scales to levels of competency are stressed on these forms. ${ }^{10}$ Whichever form is used, the key is to provide constant feedback and evaluation to the student during the experience. Comments, in addition to numbers, are critical. Most forms will contain a space for comments on general strengths, weaknesses, and what was accomplished during the experience. Some states have attempted to use these forms but have found monitoring the process to be difficult. Schools of pharmacy with experiential coordinators have been able to institute such processes and monitor them through their interactions with preceptors and students. In addition, they are also used to obtain feedback from students regarding the general experiential program. Such feedback is only useful when someone, such as an experiential program coordinator, reviews it and takes corrective action (ie, meeting with preceptor, removing a site from the program) as necessary.

The ultimate quality assurance measure is site visits. Traditionally for internship, these were conducted by state board inspectors. Although they could comment on compliance with the law, these inspectors were not trained in evaluating an educational process. As schools of pharmacy have become more involved in the experiential programs, this responsibility is being placed with the experiential program coordinators. Ideally, sites should be visited several times a year when students are assigned. Many experiential coordi-

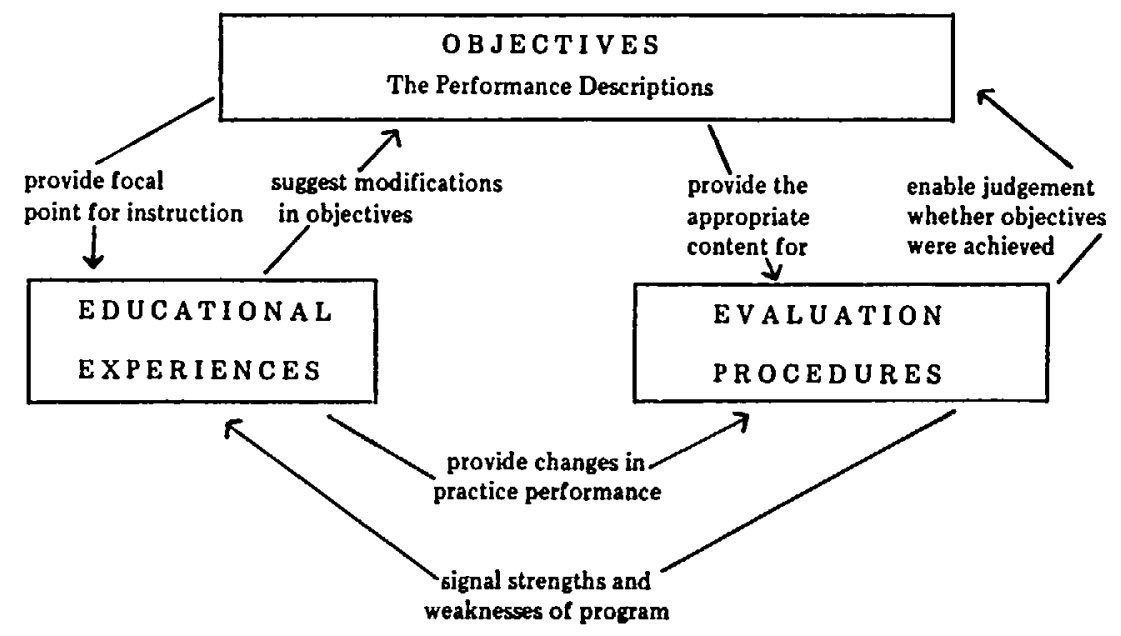

Fig 1. The relationship between objectives and evaluation by the Joint Committee on Internship. 
nators are faced with other teaching and practice commitments that preclude this. Some coordinators are able to conduct visits as frequently as once a month. Certainly, all coordinators visit sites prior to placing students and when alerted to problems.

As schools of pharmacy have instituted experiential programs, the state boards and ACPE have been an integral part of the quality assurance process. As the accrediting body, ACPE reviews the entire didactic and experiential curriculum. Current reviews have specifically focused on the experiential programs and are looking for a balance between distributive, patient oriented, administrative, and specialized areas. In addition, adequate tools to structure the program and evaluations, communications between college and preceptors, and adequate site visitation have been assessed. The state boards have one of their members participate in this process. State boards also have been active in initially approving college-based programs and determining how many hours from a collegebased program can be applied toward internship.

In conclusion, the need for education in the practice setting that is taught by actual practitio- ners is clear. Although state boards took the initial steps, schools of pharmacy are now intimately involved in this process and will continue to expand programs as resources are developed. One of the primary resources is current practitioners. Efforts to provide training and incentives to potential practitioner educators must continue. Standardization is still lacking in regards to hours required and preceptor to student ratio. Quality assurance must be maintained by all three parties (state board, ACPE, and schools of pharmacy), but the monitoring of student, site, and preceptors may be most easily handled by an experiential program coordinator at the schools of pharmacy. There is a need to develop better evaluation systems that truly indicate competency. State boards and schools of pharmacy recognize that internship and externship lay the groundwork for our future practitioners; traditional objectives must blend with those that will allow the interns to continue to develop as practitioners in their future settings. Preceptors, schools of pharmacy, and state boards face a tremendous challenge, but the result of producing competent practitioners to lead our profession is well worth the effort.

\section{REFERENCES}

1. Trinca CE: Pharmacists of the future: How can students prepare for the role. AACP News Feb:506, 1987

2. Rising LW: The Washington experiment. Am J Pharm Educ 11:257-264, 1947

3. Joint Committee on Internship of the NABP and AACP: The internship experience: A manual for pharmacy preceptors and interns. Washington, DC, NABP, 1982, p 2

4. Bylaws of the NABP, Article II, Section 4(3), Report of the Committee on Constitution and Bylaws to the 75th Annual Meeting of NABP. Washington, DC, NABP, 1979, p 105

5. ACPE: Accreditation Manual (ed 7). Chicago, IL, ACPE, 1975
6. Joint Committee on Internship of the NABP and AACP: The internship experience: A manual for pharmacy preceptors and interns. Washington, DC, NABP, 1982

7. Kalman SH, Schlegel JF: Standards of practice for the profession of pharmacy. Am Pharm 19:21-35, 1979

8. Bylaws of the NABP, Article II, Section 4, NABP Proceedings. Washington, DC, NABP, 1974, p 484

9. Joint Committee on Internship of the NABP and AACP: The internship experience: $A$ manual for pharmacy preceptors and interns. Washington, DC, NABP, 1982, pp 25-26

10. Grussing PG, Silzer RF, Cyrs TE: Development of behaviorally-anchored rating scales for pharmacy practice. Am J Pharm Educ 43:115, 1979 